\title{
LA AUTONOMÍA PROGRESIVA DE LA VOLUNTAD Y EL INTERÉS SUPERIOR \\ DE LA NIÑEZ: PRINCIPIOS QUE IMPACTAN EL SISTEMA JURÍDICO MEXICANO
}

Yesenia Guadalupe Crespo ${ }^{1}$

\section{Resumen}

Conocer el principio de autonomía progresiva como principio habilitador vinculado al interés superior de los menores, con la aplicación del método deductivo-cualitativo y desde una perspectiva holística, nos permite establecer el surgimiento de nuevos paradigmas doctrinales y normativos que transforman la administración, procuración e impartición de justicia, así como el ejercicio de los derechos a favor de los niños, niñas y adolescentes en México.

Palabras clave: Autonomía Progresiva de la Voluntad, Interés Superior, Menores de Edad, Capacidad Procesal, Sistema Jurídico.

\section{INTRODUCCIÓN}

Con la entrada en vigencia de la Convención sobre los derechos de los niños en México (CDN), se transformó la doctrina clásica y los cánones normativos existentes. De un modelo tutelar donde el menor era visto exclusivamente como objeto de protección y cuidado por parte del Estado, las instituciones y sus representantes; pasó a uno de corte garantista, en donde los menores de edad son sujetos de derechos.

\footnotetext{
${ }^{1}$ Doctora en Derecho. Profesora Investigadora de tiempo completo titular A de la División Académica de Ciencias Sociales y Humanidades, de la Universidad Juárez Autónoma de Tabasco, Miembro del Sistema Nacional de Investigadores, Perfil Deseable PRODEP. Integrante del Cuerpo Académico de Derecho Civil y del Núcleo Académico Básico de los posgrados integrados de la Maestría y Doctorado en Estudios Jurídicos, perteneciente a los programas de posgrados de calidad reconocidos por el CONACYT.E-mail: yesecres@hotmail.com
} 


\section{LOS NIÑOS, NIÑAS Y ADOLESCENTES COMO SUJETOS DE DERECHO}

La infancia definida por el fondo de las Naciones Unidad (UNICEF, 2018) es la época en la que los niños y niñas tienen que estar en la escuela y en los lugares de recreo, crecer fuertes y seguros de sí mismos y recibir el amor y el estímulo de sus familias y de una comunidad amplia de adultos. Donde la condición y calidad de vida que tienen les permite vivir y desarrollarse plenamente y sin miedo.

La Organización de las Naciones Unidas, a través de la UNICEF y otras instituciones, buscan generar las condiciones necesarias para que los niños y niñas de cualquier parte del mundo, puedan crecer en igualdad de circunstancias y desarrollarse plenamente en uso, goce y disfrute de sus derechos humanos. Sin embargo es un ideal que en la realidad no se ha concretado, pues las condiciones que cada país presenta desde su geografía, cultura, forma de gobierno, política, economía y justicia difieren unos de otros e inciden de forma positiva o negativa respecto de la calidad de vida de sus habitantes.

Cuando se habla del Estado mexicano se considera como un régimen político o como un Estado de derechos democrático, pero no solo desde la óptica de garantizar la participación ciudadana (Correas, 2003, p.46), sino por el compromiso de hacer valer los derechos humanos e incluso entender que la evolución de los mismos nos obliga a su interpretación progresiva y con ello, surge el ineludible compromiso de su defensa (Correas, 2003, p. 71), en donde se tenga como principio rector la igualdad de las personas y a su vez la defensa de todo el andamiaje institucional a tales fines.

Tratándose de los derechos de los niños, niñas y adolescentes, estos han tenido una evolución paulatina y lenta en la agenda política mexicana, así como en la normatividad que la regula, debido a que la obligación internacional de proteger a los menores de edad que se encontrasen en territorio nacional, es uno de los compromisos internacionales contraídos desde el siglo pasado, sin importar su, edad, género, religión, condición jurídica o nacionalidad; siendo incluso víctimas del Estado al encontrarnos por décadas en un desfase institucional y jurídico que regulará adecuadamente la normatividad aplicable a los menores. Sin embargo, no ha sido un problema exclusivo en México, sino de gran parte de los países del continente.

El reconocimiento de los derechos de la niñez por parte de los Estados, se ha transformado, para dejar de ser considerados como objetos de protección y control (Estado-representantes), para pasar a ser sujetos plenos de derechos (Viola, 2012, pp. 83-84); lo que trae consigo que deba priorizarse la forma de hacerlos efectivos, e incluso su participación en las actividades que le son propias; en este último aspecto vale acotar que en la actualidad también son considerados con capacidad procesal, por lo cual, nuestro sistema debe hacerse cargo de que cuenten con las garantías que les permitan ejercitarlos adecuadamente. 


\section{LA CONSTITUCIONALIZACIÓN DE LOS DERECHOS HUMANOS Y SU IMPACTO AL DERECHO MEXICANO}

El 10 de junio de 2011 (Diario Oficial de la Federación, 2011), significó para el sistema jurídico mexicano un avance en materia de derechos humanos al insertar en la carta magna de forma textual en el capítulo I, la denominación de los derechos humanos y sus garantías, haciendo hincapié en el texto constitucional, la obligatoriedad de su cumplimiento y la protección por el Estado mexicano para todas las personas sin distingo alguno; incluyendo a los niños, niñas y adolescentes.

Es menester resaltar que la constitución en el artículo 133, ya establecía con antelación a la reforma enunciada, la obligación nacida para México de cumplir con los tratados internacionales de los cuales fuese parte, incluidos por supuesto los propios a los derechos humanos y los que enarbolan los derechos de las niñas, niños y adolescentes, considerándose así a todas esas normas jurídicas en conjunto, parte integrante del esquema de la supremacía constitucional.

Sin embargo, es una realidad que aún y cuando ya existía la obligatoriedad para cumplir el compromiso de respetar y garantizar los derechos humanos, se requirió la reforma ya mencionada para que quedara claramente establecido que México tenía que cumplir con todas las obligaciones contraídas y adecuar toda su normatividad para garantizar que puedan ser ejercidos a cabalidad.

También se debe tener presente que dentro de estas reformas de orden constitucional en materia de derechos humanos, el 12 de octubre del mismo año, se reformó el artículo 4o. constitucional para incorporar el principio del interés superior de la niñez, incluyéndose a partir de la citada reforma en las políticas públicas del gobierno de México (Pérez Fuentes, 2014, pp.97-108). Y en este punto la evolución que se ha gestado se extiende de tal forma, que tratándose de los niños, niñas y adolescentes, incluso se debe velar por cumplir con los derechos y principios que los protegen, como el interés superior referido y la autonomía progresiva de la voluntad que poseen en razón de sus circunstancias específicas; correspondiéndole al Estado su salvaguarda, así como el señalar los parámetros claros para su aplicación cuando se deban realizar valoraciones normativas que puedan afectar su vida cotidiana y cualquier actividad o derechos que les sean inherentes.

Otra de las grandes transformaciones que se generó a raíz de la incorporación de los derechos humanos a la parte dogmática de la Constitución, fue la constitucionalización del derecho civil (Cantoral Domínguez, 2018); se sentaron las bases para que a partir de los derechos de las personas reconocidos como parte de los derechos fundamentales, se establecieran las directrices bajo las cuales las demás leyes aplicables, deban desarrollarse.

Como se ha tratado de esbozar, es una transformación normativa que ha impactado a todo el sistema 
jurídico y la forma de procurar e impartir justicia, pero que también se extiende a todos los demás ámbitos como la salud, la educación, la vivienda, la seguridad social, el trabajo, la migración, así como el ejercicio de libertades como la de expresión e información, el uso de las nuevas tecnologías y disposiciones en materia de protección de datos personales (Pérez Fuentes, 2018, pp. 103-119) y medio ambiente, por enunciar solo algunos; y que si bien es cierto, ya contaban con una regulación normativa, esta se ha visto compelida a evolucionar para estar en consonancia con los derechos fundamentales.

Tampoco debemos obviar que en junio de 2008 (Carbonell, 2012), se dio otra reforma que aunque no es especifica en materia de derechos humanos, si trae implícita su aplicación para alcanzar la concreción del debido proceso en materia penal, y la transición de un sistema mixto con tendencia inquisitiva, a un sistema mixto de corte acusatorio; esto sin lugar a dudas debido a la necesidad de garantizar que las partes involucradas en los procesos, gocen de los derechos y principios contenidos en la constitución y los tratados internacionales aplicables para el acceso eficaz a la justicia. Aquí podemos concluir cuatro premisas a considerar a raíz de ambas reformas y las implicaciones que conllevan:

1) La inclusión de los derechos humanos en la Constitución y su armonización normativa en todo el país;

2) La constitucionalización del derecho civil;

3) El impacto de los derechos humanos (debido proceso o garantías judiciales, como lo enuncia la Convención de Derechos humanos) al proceso no solo penal, sino a todos los procesos jurisdiccionales o administrativos, civil, familiar, mercantil, laboral, fiscal, etcétera;

4) Los derechos evolutivos de los niños niñas y adolescentes y la importancia de priorizar los principios que los rigen para crear los mecanismos indispensables para su adecuado ejercicio y protección.

Lo anterior, nos sitúa en una nueva realidad dogmática y normativa que se tiene que reflejar en la forma de procurar e impartir justicia en el país, máxime si en los procesos los menores de edad forman parte o participan de alguna forma.

Como se ha aducido, estas reformas impactaron a todo el Estado, sus instituciones, al derecho en general, pues no hay una sola área en la cual, no se tenga la obligación de su observancia y cumplimiento, tal y como lo sostiene la Suprema Corte de Justicia en la jurisprudencia cuyo rubro se denomina Derechos humanos. Obligación de protegerlos en términos del artículo 1', párrafo tercero, de la Constitución Política de los Estados Unidos Mexicanos ${ }^{2}$.

\footnotetext{
${ }^{2}$ Tesis: XXVII.3o. J/24, Semanario Judicial de la Federación y su gaceta, Decima época, Tomo III, Libro 15, Febrero de 2015, p. 2254. Esta tesis se publicó el viernes 20 de febrero de 2015 a las 09:30 horas en el Semanario Judicial de la Federación y, por ende, se considera de aplicación obligatoria a partir del lunes 23 de febrero de 2015.
} 
Sin lugar a dudas, la inclusión en el texto constitucional del capítulo específico de los derechos humanos ha sido un avance para la justicia en México, quizá el mayor en el último siglo; no obstante, sigue siendo por si solo insuficiente, pues no hay que perder la objetividad y tener presente que para que una reforma sea realmente funcional, el aparato de justicia debe funcionar integralmente y todas sus piezas y engranajes trabajar al mismo ritmo y con los mismos lineamientos y en ello radica una parte esencial del compromiso asumido para el sistema jurídico mexicano y en el cual debe seguirse trabajando para su cumplimiento, dado que legislar no implica que se esté cumpliendo, para ello deben crearse políticas públicas concretas que permitan alcanzar dicho objetivo.

\section{MARCO JURÍDICO PARA LA PROTECCIÓN DE LOS NIÑOS, NIÑAS Y ADOLESCENTES}

Existen numerosos instrumentos internacionales y nacionales expedidos para la protección de los menores, obligatorios todas las autoridades mexicanas; tratándose de los internacionales como ya se mencionó, la obligatoriedad de su cumplimiento nace para aquellos que han sido firmados y ratificados por el Estado y; en cuanto los nacionales, son todos aquellos expedidos por el poder legislativo.

Analizaremos sin ser exhaustivos y debido a la extensión del presente trabajo, los que consideramos son parte de las directrices de las normas vigentes, incluyendo importantes regulaciones aun y cuando se emitieron en el siglo pasado, pero que ya contemplaban una protección plena para los menores de edad.

\section{Marco jurídico internacional}

El párrafo tercero del artículo 1o. de la Constitución Política de los Estados Unidos Mexicanos dispone como obligaciones generales de las autoridades del Estado Mexicano las consistentes en: i) Respetar; ii) Proteger; iii) Garantizar; y, iv) Promover los derechos humanos, de conformidad con los principios rectores de universalidad, interdependencia, indivisibilidad y progresividad. De ahí que para determinar si una conducta específica de la autoridad importa violación a derechos fundamentales, debe evaluarse si se apega o no a la obligación de garantizarlos; y como la finalidad de esta obligación es la realización del derecho fundamental, requiere la eliminación de restricciones al ejercicio de los derechos, así como la provisión de recursos o la facilitación de actividades que tiendan a lograr que todos se encuentren en aptitud de ejercer sus derechos fundamentales. La índole de las acciones dependerá del contexto de cada caso en particular; así, la contextualización del caso particular requiere que el órgano del Estado encargado de garantizar la realización del derecho tenga conocimiento de las necesidades de las personas o grupos involucrados, lo que significa que debe atender a la situación previa de tales grupos o personas y a las demandas de reivindicación de sus derechos. Para ello, el órgano estatal, dentro de su ámbito de facultades, se encuentra obligado a investigar, sancionar y reparar las violaciones a derechos humanos que advierta, de forma que su conducta consistirá en todo lo necesario para lograr la restitución del derecho humano violentado. Por tanto, su cumplimiento puede exigirse de inmediato (mediante la reparación del daño) o ser progresivo. En este último sentido, la solución que se adopte debe atender no sólo al interés en resolver la violación a derechos humanos que enfrente en ese momento, sino también a la finalidad de estructurar un entorno político y social sustentado en derechos humanos. Esto implica pensar en formas de reparación que, si bien tienen que ver con el caso concreto, deben ser aptas para guiar más allá de éste. 
En la actualidad existe una vasta positivización del derecho tanto internacional como nacional, y es que solo siendo obligatorio su cumplimiento es que se empezó a regular los derechos específicamente para los niños, niñas y adolescentes, necesarios para que se desarrollen en los diferentes ámbitos de la vida pública y privada; considerando incluso las circunstancias especiales que pudiesen surgir como discapacidad, pertenencia a grupos vulnerables, o ya sea como víctimas de delitos o generadores de ellos; también se tomaron como parámetros las condiciones de marginación y migración por citar algunos ejemplos enunciativos mas no limitativos.

Otro de los aspectos que podemos resaltar, es que debido a la obligación surgida, también se ha propiciado la uniformidad de conceptos y principios indispensables para interpretar la ley en el sentido más favorable para los menores, para tratar de cubrir todas sus necesidades básicas, y a su vez, generar las condiciones necesarias para su correcto desarrollo.

Lo que poco a poco se ha trabajado, pero que si nos vamos a la literalidad de las leyes en la materia y se contrastan con la realidad social, falta un largo camino para alcanzarlos.

\section{Declaración de Ginebra}

Tradicionalmente se invoca como primer ordenamiento para análisis en materia de derechos, la Declaración Universal de los Derechos humanos, sin embargo en esta ocasión, se hará alusión debido a la temática y su transcendencia hasta el día de hoy, a la Declaración de Ginebra de 1923, redactada por Eglantine Gebb, fundadora de Save the Children Fundy la Unión Internacional del Socorro a los niños, en cuyo texto se lee: Por la presente declaración de los Derechos del Niño, los hombres y las mujeres de todos los países reconocen que la humanidad debe dar al niño todo lo que tiene de mejor ... sin distinción de raza, nacionalidad o creencia (Castillo López, 2006, p. 22). Faltaban 25 años para que se emitiera la Declaración Universal y, esta Declaración, ya enarbolaba la protección más amplia para los niños y conminaba a los Estados y a las personas, a velar y cuidar de ellos.

Parece increíble que siendo uno de los primeros documentos internacionales que ya contemplaban las circunstancias especiales de los menores de edad, respecto de su condición en desarrollo y la necesidad de protección por parte de sus padres, de las personas en general y del Estado; haya transcurrido la mayor parte del siglo XX, sin criterios uniformes para crear leyes especiales para los menores de edad y sin la real voluntad de los Estados para su regulación, situando a los menores de edad por mucho tiempo como objetos del derecho y no como sujetos de derechos. 


\section{$\underline{\text { Declaración Universal de los Derechos Humanos }}$}

Con la Declaración Universal de los Derechos Humanos aprobada en 1948, se asentó en el artículo 1, que todos los hombres nacen libres e iguales en dignidad ... (Castillo López, 2006, pp. 10-21), específicamente no hace alusión a niños o menores de edad, pero es claro que debe considerarse e interpretarse en el contexto más amplio y garantista para todas las personas. Es por excelencia uno de los documentos más consultados y eje rector de las correspondientes Convenciones sobre derechos humanos, así como la Carta de Derechos, de donde se derivan los derechos fundamentales que hoy en día siguen estudiándose e interpretándose para hacerlos congruentes con la realidad social y con las necesidades de las personas, en aras de fortalecer la fraternidad, la paz y la igualdad entre los congéneres, por enunciar algunos de sus postulados y en contra de toda forma de discriminación, maltrato o explotación. Su interpretación en sentido holístico nos permite afirmar la integralidad de sus disposiciones hacia todo ser humano, incluidos los niños.

\section{Declaración de la Unión Internacional de Protección a la Infancia}

En Agosto de 1948 se efectuó en Estocolmo un Congreso en donde se redactaron modificaciones a la Declaración de Ginebra, y se emitió la Declaración de la Unión Internacional de Protección a la Infancia, debido a la necesidad de regular con mayor amplitud en la materia, estableciéndose específicamente la obligación de proteger al niño por encima de toda consideración de raza, nacionalidad o de creencia, tomando en cuenta su medio familiar y las exigencias de la seguridad social. Pero fue hasta 1959 que la Asamblea General de las Naciones Unidas considero que las necesidades de la infancia justificaban una nueva instrumentación independiente, lo que dio nacimiento a la Declaración de los derechos del niño, con la finalidad de que bajo estas pautas los niños pudiesen alcanzar una vida feliz (Castillo López, 2006, p. 23). En ella se plasman una serie de derechos que todo niño o niña debe gozar y prioriza la protección especial y necesaria en razón de la minoría de edad y en beneficio de su normal desarrollo, bienestar y felicidad.

$\underline{\text { Pacto Internacional de Derechos Civiles y Políticos y el Pacto Internacional de Derechos }}$ Económicos, Sociales y Culturales

El 23 de marzo de 1981 México ratifica el Pacto Internacional de Derechos Civiles y Políticos y el Pacto Internacional de Derechos Económicos, Sociales y Culturales, en lo que atañe a los niños, el primero en el artículo 
24 señala que los menores no deben ser discriminados por ningún motivo, siendo enunciativo mas no limitativo, la raza, color, sexo, idioma, religión o cualquier otra circunstancia que pudiera presentarse (Castillo López, 2006, pp. 24, 25).

En cuanto al Pacto internacional de derechos económicos, sociales y culturales, aunque no aborda específicamente a los menores, no implica que no se interprete en sentido amplio la inclusión de los niños y niñas en cuanto dispone que toda persona tenga el derecho a gozar de un nivel de vida adecuado, a vestido, alimentación y vivienda y a los Estados a proporcionar los medios para garantizarlos, es decir, carecería de toda lógica pensar que los menores de edad, no deben gozar de los derechos económicos, sociales y culturales. Como se ha ido estudiando, la legislación que aplica a la protección de los menores de edad como sujetos de derechos es basta, y requiere de la instrumentación necesaria para que se puedan cumplir íntegramente y alcanzar así la finalidad para la cual fueron creados y lo que podría coadyuvar en la erradicación de los componentes que los sitúan incluso dentro de los grupos vulnerables.

\section{Convención sobre los derechos del niño}

En 1990 México ratifica la Convención sobre los derechos del niño, obligándose a crear las condiciones indispensables para que puedan desarrollarse de forma integral, con un nivel de vida adecuado y de crecer en un ambiente armonioso, extendiéndose por supuesto a cualquier niño, niña o adolescente con independencia de su estatus migratorio, raza, religión, idioma, creencia, color, sexo, opinión política o de otra índole, origen étnico o social, posición económica, impedimentos físicos, o cualquier otra condición del niño y que las autoridades deben garantizar priorizando el interés superior de menor.

A decir de la UNICEF, la Convención es el primer tratado internacional de derechos humanos que combina en un instrumento único una serie de normas universales relativas a la infancia, y el primero en considerar los derechos de la niñez como una exigencia con fuerza jurídica obligatoria. Y a los niños como sujetos de derechos y capacidad procesal.

\section{Convención Americana sobre Derechos Humanos}

En cuanto a la Convención Americana de Derechos Humanos, que rige para los países pertenecientes a la Organización de los Estados Americanos (OEA) y cuya competencia jurisdiccional es la Corte interamericana de Derechos humanos, instrumento que se ratificó en 1981 y por ende, es parte de las leyes supremas de país siguiendo el principio establecido en el artículo 133 de la Constitución Federal; por lo que de acuerdo al artículo 
1.1, de la Convención, es deber del Estado mexicano garantizar el respeto de los derechos humanos sin discriminación ... y en relación al artículo 19, se impone la obligación de que adopte las medidas necesarias de protección a favor de todo niño, niña y adolescente.

Por ello, no es una potestad sino una obligación, que las autoridades administrativas como el formado por el Sistema Nacional para el Desarrollo Integral de la Familia, las autoridades estatales y municipales, así como de cualquier otra autoridad administrativa o jurisdiccional que tenga facultades para atender los asuntos en materia de menores, conozca y ponga en práctica las acciones que orienten a la aplicación adecuada de las medidas necesarias para el pleno disfrute y ejercicio adecuado de los derechos de los niños sin importar su condición o circunstancia, por tal motivo incluso si es necesario decretar otras medidas consideradas especiales o dicho de otra forma, más específicas, que las tradicionales que se mandatan para el resto de las personas, el Estado deberá contemplar los medios que permitan crearlas y ejecutarlas.

\section{Marco jurídico nacional}

Cuando se analiza el marco jurídico nacional, por cuestiones de jerarquía, se inicia con la Constitución Política de los Estados Unidos Mexicanos, sin embargo, esta ya ha sido analizada en el apartado II, debido a que se relacionó con la reforma de 2011 en materia de derechos humanos y la trasformación que generó en el sistema jurídico mexicano a nivel normativo e interpretativo, en donde un derecho se analiza e interpreta en forma sistemática, respetando el principio pro persona, y garantizando el respecto de los niños, niñas y adolescentes, donde también es indispensable que se interpreten todas las normas, y se privilegie el interés superior del menor y la autonomía progresiva de sus derechos, en razón del bloque de constitucionalidad surgido o a decir de la Corte, en base a los parámetros de regularidad constitucional, así como de las obligaciones contraídas en el plano internacional.

\section{Ley General de los Derechos de las niñas, niños y adolescentes}

Es una Ley de orden público, que se promulgó en el año 2014 y que inspirada en los acuerdos internacionales en materia de derechos humanos de los cuales México es parte, prevé los derechos y garantías que son de aplicación obligatoria en toda la República mexicana para los niños, niñas y adolescentes, como titulares de derechos, de conformidad con los principios de universalidad, interdependencia, indivisibilidad y progresividad propios de los derechos humanos y, en consonancia con la reforma constitucional de 2011, específicamente en el artículo 1 y del 4, tratándose de priorizar la aplicación del interés superior del menor, tal y como prevé la tesis 
emitida por la segunda sala de la Suprema Corte de Justicia ${ }^{3}$.

Por tal motivo, las autoridades federales, estatales y municipales, en el ámbito de sus respectivas competencias, están obligadas a adoptar medidas de protección especial para hacer efectivo los derechos de niñas, niños y adolescentes, incluidos los que se encuentren en situación de vulnerabilidad por circunstancias específicas de carácter socioeconómico, alimentario, psicológico, físico, discapacidad, identidad cultural, origen étnico o nacional, situación migratoria o apátrida, o bien, relacionadas con aspectos de género, preferencia sexual, creencias religiosas o prácticas culturales, u otros que restrinjan o limiten el ejercicio de sus derechos (Cantoral Dominguez, 2015, pp. 56-75). Criterio que reitera a los menores de edad como sujetos de derechos, los cuales no son limitativos; al contrario, existe por parte del Estado y las personas relacionadas con los menores, padres, tutores o cualesquiera de sus representantes en general, encontrar e incluso crear los medios y las condiciones que sean eficaces para que puedan ejercitarlos libres y adecuadamente.

\section{LA AUTONOMÍA PROGRESIVA COMO PRINCIPIO HABILITADOR Y SU VINCULACIÓN CON EL INTERÉS SUPERIOR DEL MENOR}

La protección integral para los menores de edad por parte del Estado, aunado a la obligación de dotarlos de los medios y las condiciones para poder ejercer sus derechos, en donde se privilegien los principios de autonomía progresiva y de interés superior, es un parteaguas en el sistema jurídico mexicano, que ha añadido un cambio paradigmático en la administración, procuración e impartición de justicia y en el derecho en general, para los niños, niñas y adolescentes.

Dentro de los aportes de la Convención $(\mathrm{CDN})$ a la realidad jurídica, se hallan límites a la intervención

\footnotetext{
${ }^{3}$ Tesis: 2a. CXLI/2016, Semanario judicial de la Federación y su Gaceta, Décima Época, Tomo I Libro 38, Enero de 2017, p. 792. DERECHOS DE LAS NIÑAS, NIÑOS Y ADOLESCENTES. EL INTERÉS SUPERIOR DEL MENOR SE ERIGE COMO LA CONSIDERACIÓN PRIMORDIAL QUE DEBE DE ATENDERSE EN CUALQUIER DECISIÓN QUE LES AFECTE. El artículo 2, segundo párrafo, de la Ley General de los Derechos de Niñas, Niños y Adolescentes prevé que el "interés superior de la niñez deberá ser considerado de manera primordial en la toma de decisiones sobre una cuestión debatida que involucre niñas, niños y adolescentes"; de ahí que cuando se tome una decisión que les afecte en lo individual o colectivo, "se deberán evaluar y ponderar las posibles repercusiones a fin de salvaguardar su interés superior y sus garantías procesales". Al respecto, debe destacarse que el interés superior del menor es un concepto triple, al ser: (I) un derecho sustantivo; (II) un principio jurídico interpretativo fundamental; y (III) una norma de procedimiento. El derecho del interés superior del menor prescribe que se observe "en todas las decisiones y medidas relacionadas con el niño", lo que significa que, en "cualquier medida que tenga que ver con uno o varios niños, su interés superior deberá ser una consideración primordial a que se atenderá", lo cual incluye no sólo las decisiones, sino también todos los actos, conductas, propuestas, servicios, procedimientos y demás iniciativas. Así, las decisiones particulares adoptadas por las autoridades administrativas -en esferas relativas a la educación, el cuidado, la salud, el medio ambiente, las condiciones de vida, la protección, el asilo, la inmigración y el acceso a la nacionalidad, entre otras- deben evaluarse en función del interés superior del niño y han de estar guiadas por él, al igual que todas las medidas de aplicación, ya que la consideración del interés superior del niño como algo primordial requiere tomar conciencia de la importancia de sus intereses en todas las medidas y tener la voluntad de dar
} 
de los adultos en algunos aspectos propios a la vida privada o pública del menor.

Ahora bien, respecto del principio de autonomía progresiva, tiene sus bases en los artículos 5 y 12 de la CND. En el primero, se establece que los menores “... en consonancia con la evolución de sus facultades, dirección y orientación apropiada, ejercerán sus derechos ... " ". En el segundo artículo, se consagra la obligación del Estado de garantizar "... al niño que esté en condiciones de formarse un juicio propio, el derecho de expresar su opinión libremente ... 5". También se enfatiza la importancia de tener en cuenta sus opiniones, las cuales para valoración, debe tomar como parámetro la edad y madurez que posee el menor, de lo cual se desprende que para la aplicación de este principio, debe tamizarse, caso por caso; lo anterior, si partimos del supuesto que debemos ponderar el grado de desarrollo físico e intelectual que cada niño a alcanzado, y que, vinculado al principio de interés superior, existe la exigencia de incluir las condiciones y características de cada niño en particular; a contrarios sensu, no hacerlo, implicaría volver al esquema arbitrario en donde el menor es objeto del derecho y no sujeto del mismo.

El rol del Estado y de los adultos en la formación, acompañamiento, orientación y protección de los niños no cesa, sino que disminuye gradualmente conforme avanza el progreso evolutivo del niño para ejercer sin restricciones o representaciones sus derechos, y no estar a la espera de la condicionante de la mayoría de edad para poder ejercer los que correspondan en función de su progresividad mostrada.

La autonomía implica la capacidad de autodeterminarse, de independencia y de libertad para pensar, para actuar y para decidir (Lobos, 2015, pp. 4-7); y la progresividad supone un avance gradual; por lo que la autonomía progresiva debe entenderse como esa evolución en donde los niños conforme desarrollan su capacidad de comprensión, de conocimiento del mundo inteligible, del factico y de las experiencias que conllevan, adquieren mayor grado de madurez; lo que les permite ejercer en mayor o menor medida según cada caso en particular, por si mismos sus derechos.

Debemos tomar en consideración que elementos como: la edad, el medio social, el económico y el

prioridad a esos intereses en todas las circunstancias, pero sobre todo cuando las medidas tengan efectos indiscutibles en los niños de que se trate.

${ }^{4}$ Artículo 5 de la CDN.

Los Estados Partes respetarán las responsabilidades, los derechos y los deberes de los padres o, en su caso, de los miembros de la familia ampliada o de la comunidad, según establezca la costumbre local, de los tutores u otras personas encargadas legalmente del niño de impartirle, en consonancia con la evolución de sus facultades, dirección y orientación apropiadas para que el niño ejerza los derechos reconocidos en la presente Convención.

${ }^{5}$ Artículo 12 de la CDN

1. Los Estados Partes garantizarán al niño que esté en condiciones de formarse un juicio propio el derecho de expresar su opinión libremente en todos los asuntos que afectan al niño, teniéndose debidamente en cuenta las opiniones del niño, en función de la edad y madurez del niño.

2. Con tal fin, se dará en particular al niño oportunidad de ser escuchado en todo procedimiento judicial o administrativo que afecte al niño, ya sea directamente o por medio de un representante o de un órgano apropiado, en consonancia con las normas de procedimiento de la ley nacional. 
cultural, así como la aptitud de cada niño, son indispensables para aplicar adecuadamente los principios analizados.

La aplicación de estos principios es compleja sin lugar a dudas, implica un cambio en la forma tradicional de su tratamiento, tanto en lo individual como en lo social; conlleva una responsabilidad para el Estado, las instituciones, los padres, tutores o representantes y adultos en general, con quienes interactúe el menor; pero también para el niño, quien en forma proporcional al desarrollo de esta autonomía progresiva, será responsable legal de sus actuaciones (Fernández Espinoza, 2017).

La Suprema Corte de Justicia de la Nación (SCJN) concibe la evolución progresiva de las facultades del niño como un principio habilitador para el ejercicio de sus derechos ${ }^{6}$, en donde la tradición de tratamiento a los menores como incapaces sin poder de decisión, ha terminado, para avanzar al reconocimiento y disfrute efectivo de sus derechos. Y aquí nos encontramos frente a otra realidad, no sólo ha evolucionado la forma en que el Estado, los padres y los adultos deben considerar al menor, sino también debemos considerar que a la par se gestó un cambio paradigmático en la teoría clásica respecto de la capacidad de ejercicio que tienen los menores de edad.

El término incapacidad aplicable a los menores hasta antes de cumplir la mayoría de edad (18 años en México) deja de tener aplicabilidad y presenta un desfase; no es que desaparezca por completo de la doctrina o de la norma; sino que debemos dejar de interpretarlo como algo estático, en sentido contrario, conforme el menor adquiera mayores niveles de conocimiento, aprendizaje, experiencia y madurez, su incapacidad se reducirá y no dependerá exclusivamente del alcance de la edad legal para ejercer por sí mismo sus derechos.

Otro supuesto que debemos tener presente como ya se analizó, es la capacidad de ejercicio de los menores, que evoluciona progresivamente y que actualmente si lo meditamos, tiene reconocimiento en las leyes al otorgarles capacidad procesal en determinadas áreas del derecho o para determinados actos jurídicos.

La participación activa de los menores en los procesos jurisdiccionales se da, salvaguardando su

\footnotetext{
${ }^{6}$ Tesis: 2a. XI/2018 (10a.), Gaceta del Semanario Judicial de la Federación, Libro 50, 19 de enero de 2018, Tomo I, 539. EVOLUCIÓN PROGRESIVA DE LAS FACULTADES DEL NIÑO. CONSTITUYE UN "PRINCIPIO HABILITADOR" DEL EJERCICIO DE SUS DERECHOS. El ejercicio de los derechos de los menores no puede concebirse de manera idéntica para toda etapa de la niñez, pues cada una presenta un grado diferenciado de libertades y deberes respecto a su realización: a mayores niveles de aprendizaje, conocimiento y madurez, mayor el margen de autonomía para que sean los menores quienes ejerzan, por sí mismos, sus derechos -y no simplemente por medio de sus padres-; de ahí que tanto la pertinencia, como el grado de acceso a los derechos de los niños, dependerá de la etapa de la niñez en la que se encuentre el menor y, por ende, a efecto de lograr su correcta consecución, debe atenderse en todo momento a su trayectoria vital, a lo que le resulte benéfico y permita el desarrollo pleno y efectivo de todos sus derechos. Es así, en virtud de que el artículo 5 de la Convención sobre los Derechos del Niño establece que los Estados Partes respetarán las responsabilidades, los derechos y los deberes de los padres de impartirle, en consonancia con la evolución de sus facultades, dirección y orientación apropiadas para que el niño ejerza los derechos reconocidos en dicha Convención. En ese contexto, es menester concebir a la evolución progresiva de las facultades de los menores como un verdadero "principio habilitador" de la totalidad de los derechos reconocidos por el parámetro de regularidad del Estado Mexicano, y no como una excusa para realizar prácticas autoritarias que restrinjan la autonomía del niño y que tradicionalmente se han justificado, alegando la relativa inmadurez del menor.
} 
integridad y tomando en consideración su edad y mayor o menor grado de madurez. La SCJN sostiene que reviste una doble finalidad el ejercicio efectivo de sus derechos y a la vez, permite que al juzgador allegarse de todos los elementos que necesite para forjar su convicción respecto de un caso concreto, estableciendo que solo así se puede tutelar efectivamente el interés superior de $\operatorname{los}_{\text {niños }}^{7}$ y añadiremos, hacer valida efectivamente la autonomía progresiva de la voluntad.

\section{CONCLUSIONES}

La incorporación de los derechos fundamentales al marco jurídico mexicano, ha contribuido a los cambios de paradigma que tradicionalmente operaron en nuestro sistema. Tratándose de menores de edad una de las transformaciones ha sido que de ser objetos del derecho, hoy en día podemos situarlos como sujetos de

${ }^{7}$ Tesis: 12/2017 (10a.). Gaceta del Semanario Judicial de la Federación, Libro 40, Marzo de 2017, Tomo I, p. 288.

Las niñas y los niños, como titulares de derechos humanos, ejercen sus derechos progresivamente, a medida que desarrollan un mayor nivel de autonomía, lo que se denomina "adquisición progresiva de la autonomía de los niños", lo cual conlleva que actúen durante su primera infancia por conducto de otras personas -idealmente, de sus familiares-. Así, el derecho de las niñas y los niños a participar en procedimientos jurisdiccionales que puedan afectar su esfera jurídica se ejerce, también, progresivamente, sin que su ejercicio dependa de una edad que pueda predeterminarse en una regla fija, incluso de índole legal, ni aplicarse en forma generalizada a todos los menores de edad, sino que el grado de autonomía debe analizarse en cada caso. Ahora bien, la participación de los niños en procedimientos jurisdiccionales reviste una doble finalidad, pues, al reconocerlos como sujetos de derecho, logra el efectivo ejercicio de sus derechos $y$, a la vez, se permite que el juzgador se allegue de todos los elementos que necesite para forjar su convicción respecto de un determinado asunto, lo que resulta fundamental para una debida tutela del interés superior de la infancia. En este sentido, los lineamientos que deben observarse para la participación de niñas y niños dentro de cualquier procedimiento jurisdiccional que pueda afectar su esfera jurídica son: (1) para la admisión de la prueba debe considerarse que: (a) la edad biológica de los niños no es el criterio determinante para llegar a una decisión respecto a su participación dentro de un procedimiento jurisdiccional, sino su madurez, es decir, su capacidad de comprender el asunto, sus consecuencias y de formarse un juicio o criterio propio; (b) debe evitarse la práctica desconsiderada del ejercicio de este derecho; y, (c) debe evitarse entrevistar a los niños en más ocasiones de las necesarias; (2) para preparar la entrevista en la que participarán, se requiere que sean informados en un lenguaje accesible y amigable sobre el procedimiento y su derecho a participar, y que se garantice que su participación es voluntaria; (3) para el desahogo de la prueba, la declaración o testimonio del niño debe llevarse a cabo en una diligencia seguida en forma de entrevista o conversación, la cual debe cumplir con los siguientes requisitos: (a) es conveniente que previamente a la entrevista el juzgador se reúna con un especialista en temas de niñez, ya sea psiquiatra o psicólogo, para aclarar los términos de lo que se pretende conversar con el niño, para que a éste le resulte más sencillo de comprender y continuar la conversación; (b) la entrevista debe desarrollarse, en la medida de lo posible, en un lugar que no represente un ambiente hostil para los intereses del niño, esto es, donde pueda sentirse respetado y seguro para expresar libremente sus opiniones; (c) además de estar presentes el juzgador o funcionario que tome la decisión, durante la diligencia deben comparecer el especialista en temas de niñez que se haya reunido con el juzgador y, siempre que el niño lo solicite o se estime conveniente para proteger su superior interés, una persona de su confianza, siempre que ello no genere un conflicto de intereses; (d) en la medida de lo posible, debe registrarse la declaración o testimonio de las niñas y niños íntegramente, ya sea mediante la transcripción de toda la diligencia o con los medios tecnológicos al alcance del juzgado o tribunal que permitan el registro del audio; (4) los niños deben intervenir directamente en las entrevistas, sin que ello implique que no puedan tener representación durante el juicio, la cual recaerá en quienes legalmente estén llamados a ejercerla, salvo que se genere un conflicto de intereses, en cuyo caso debe analizarse la necesidad de nombrar un tutor interino; y (5) debe consultarse a los niños sobre la confidencialidad de sus declaraciones, aunque la decisión final sea del juzgador, para evitarles algún conflicto que pueda afectar su salud mental o, en general, su bienestar. Finalmente, es importante enfatizar que en cada una de estas medidas siempre debe tenerse en cuenta el interés superior de la infancia por lo que no debe adoptarse alguna 
derechos plenos, incluida la capacidad procesal para poder garantizar su disfrute, en base al reconocimiento gradual a la capacidad de ejercicio que poseen, ponderada en razón a los principios de autonomía progresiva de la voluntad y de interés superior, sin que la edad constituya la regla fija sobre la cual debe realizarse la valoración.

Sin embargo, no solo evolucionó la capacidad como tal; la transformación que inició, abarca todos los ámbitos en los que el menor participa, ya sea público o privado; trayendo consigo la obligación del Estado, las instituciones, padres, representantes y adultos en general, de garantizar su integración, orientación y protección, así como de facilitar los medios para su concreción.

\title{
THE PROGRESSIVE AUTONOMY OF THE WILL AND THE BEST INTERESTS OF CHILDREN: PRINCIPLES THAT IMPACT THE MEXICAN LEGAL SYSTEM
}

\begin{abstract}
Knowing the principle of progressive autonomy as an enabling principle linked to the best interests of minors, with the application of the deductive-qualitative method and from a holistic perspective, allows us to establish the emergence of new doctrinal and normative paradigms that transform administration, procurement and delivery of justice, as well as the exercise of rights in favor of children and adolescents in Mexico.
\end{abstract}

Keywords: progressive autonomy of the will, superior interest, minors, procedural capacity, legal system.

\section{REFERENCIAS}

CANTORAL DOMÍNGUEZ, Karla. "Algunos tipos de responsabilidad civil: acoso escolar, médica y por servicios defectuosos", en Pérez Fuentes, Gisela (coord.). Temas actuales de responsabilidad civil. México. Tirant lo blach. 2018.

"El derecho a la identidad del menor: el caso México". Revista Bolivariana de derecho, Colombia, no 20, julio 2015, pp. 56-75. [Consulta: el 10 de junio de 2018]. Disponible en:

determinación que implique perjuicio para los niños, más allá de los efectos normales inherentes a su participación dentro del procedimiento jurisdiccional. 
http://www.scielo.org.bo/pdf/rbd/n20/n20_a03.pdf

CARBONELL, Miguel. “Constitución Política de los Estados Unidos Mexicanos”. 168 ed., México. Porrúa. 2012.

CASTILLO LÓPEZ, Juan Antonio. "Justicia de menores en México. El desfase institucional y jurídico. México. Porrúa. 2006.

CORREAS, Oscar. Acerca de los derechos humanos. Apuntes para un ensayo. México. Ediciones Coyoacán. UNAM. 2003.

DIARIO OFICIAL DE LA FEDERACIÓN. "Decreto por el que se modifica la denominación del Capítulo I del Título Primero y reforma diversos artículos de la Constitución Política de los Estados Unidos Mexicanos", publicado el 10 de junio de 2011. [Consultado: 26 de abril de 2017]. Disponible en: http://dof.gob.mx/nota_detalle.php?codigo=5194486\&fecha=10/06/2011

FERNÁNDEZ ESPINOZA, William. "La autonomía progresiva del niño y su participación en el proceso judicial”. Revista VOX JURIS. Perú. No. 34, 2, 2017. [Consulta: el 05 de agosto de 2018]. Disponible en: http://www.repositorioacademico.usmp.edu.pe/bitstream/usmp/2805/1/fernadez_ewh2

FONDO DE LAS NACIONES UNIDAS PARA LA INFANCIA. Agencia especializada de la Organización de Naciones Unidas. 11 de diciembre de 1946. [Consulta: 15 de julio de 2018]. Disponible en: https://www.unicef.org/es http://dof.gob.mx/nota_detalle.php?codigo=5194486\&fecha=10/06/2011

LOBOS, Daniela y GONZÁLEZ, Paloma. "Autonomía progresiva y ejercicio de derechos, Observatorio niñez y adolescencia". Chile. 2015. pp. 4-7. [Consulta: el 05 de agosto de 2018]. Disponible en: http://www.xn-observatorioniez-kub.cl/wp-content/uploads/2015/07/cuaderno-autonomia-observatorio-1.pdf

ORGANIZACIÓN DE LAS NACIONES UNIDAS. Convención sobre los derechos del niño. Aprobado el 19 de junio de 1990 y con entrada en vigencia el 25 de enero de 1991 en México. [Consulta: el 20 de agosto de 2018].

Disponible

en:

http://www.cndh.org.mx/sites/all/doc/Programas/Provictima/1LEGISLACI\%C3\%93N/3InstrumentosInter 
nacionales/F/convencion_derechos_nino.pdf

Pérez Fuentes, Gisela (coord.). "Responsabilidad por daños a la persona: daño moral" Temas actuales de responsabilidad civil. México. Tirant lo blach. 2018.

“La protección de los niños migrantes en México: una falacia”. Barataria. Revista Castellano-Manchega de Ciencias Sociales. No 17, 2014. pp. 97-108. [Consulta: 17 de marzo de 2018]. Disponible en: http://www.redalyc.org/pdf/3221/322132552007.pdf

Tesis: 12/2017 (10a.). Gaceta del Semanario Judicial de la Federación, Libro 40, Marzo de 2017, Tomo I, p. 288. [Consulta: el 05 de agosto de 2018]. Disponible en: https://sjf.scjn.gob.mx/sjfsist/Paginas/ResultadosV2.aspx?Epoca=1e3e10000000000\&Apendice $=1000000000$ 000\&Expresion=autonomia\%20progresiva\%20\&Dominio=Rubro,Texto \&TATJ=2\&Orden=1\&Clase=TesisBL $\& b c=J u r i s p r u d e n c i a . R e s u l t a d o s \&$ TesisPrincipal $=$ TesisPrincipal $\&$ InstanciasSeleccionadas=6,1,2,50,7\&Hits $=20$

Tesis: 2a. CXLI/2016, Semanario judicial de la Federación y su Gaceta, Décima Época, Tomo I Libro 38, Enero de 2017, p. 792. [Consulta: el 05 de agosto de 2018]. Disponible en: https: / /sjf.scjn.gob.mx/sjfsist/Paginas/ResultadosV2.aspx?Epoca $=1$ e3e10000000000\&Apendice $=1000000000$ 000\&Expresion=autonomia\%20progresiva\%20\&Dominio=Rubro,Texto\&TATJ=2\&Orden=1\&Clase $=$ TesisBL $\& b c=J u r i s p r u d e n c i a . R e s u l t a d o s \&$ TesisPrincipal $=$ TesisPrincipal $\&$ InstanciasSeleccionadas=6,1,2,50,7\&Hits $=20$

Tesis: 2a. XI/2018 (10a.), Gaceta del Semanario Judicial de la Federación, Libro 50, 19 de enero de 2018, Tomo I, 539. [Consulta: el 05 de agosto de 2018]. Disponible en: https://sjf.scjn.gob.mx/sjfsist/Paginas/ResultadosV2.aspx?Epoca $=1$ e3e10000000000\&Apendice $=1000000000$ 000\&Expresion=autonomia\%20progresiva\%20\&Dominio=Rubro,Texto\&TATJ=2\&Orden $=1 \&$ Clase $=$ TesisBL $\& b c=$ Jurisprudencia.Resultados\&TesisPrincipal=TesisPrincipal $\&$ InstanciasSeleccionadas=6,1,2,50,7\&Hits=20

Tesis: XXVII.3o. J/24, Semanario Judicial de la Federación y su gaceta, Decima época, Tomo III, Libro 15, Febrero de 2015, p. 2254. Esta tesis se publicó el viernes 20 de febrero de 2015 a las 09:30 horas en el Semanario Judicial de la Federación y, por ende, se considera de aplicación obligatoria a partir del lunes 23 de febrero de 2015, para los efectos previstos en el punto séptimo del Acuerdo General Plenario 19/2013, [consultado: el 15 de agosto de 2018]. Disponible en: http://200.38.163.178/SJFSem/Paginas/SemanarioIndex.aspx 
VIOLA, Sabrina. "Autonomía progresiva de los niños, niñas y adolescentes en el Código Civil: una deuda pendiente". Revista Cuestión de Derechos. Argentina. No. 3. Segundo semestre 2012. pp. 83 y 84. [Consulta: 14 de agosto de 2018].

Disponible

en:

http://www.psi.uba.ar/academica/carrerasdegrado/psicologia/sitios_catedras/electivas/816_rol_psicologo/ material/unidad2/obligatoria/autonomia_progresiva_ni\%Flos_new.pdf

Trabalho enviado em 07 de setembro de 2018

Aceito em 03 de novembro de 2018 